\title{
Effects of organic cultivation with and without pest management of Adzuki bean (Vigna angularis) on yield characteristics, seed chemical composition, and antioxidant capacity
}

\author{
Chin-Jin Hou ${ }^{1}$, Zheng-Chieh Chen ${ }^{1}$, Shu-Huei Ferng ${ }^{2}$ and Hui-Fen Liao ${ }^{3 *}$ \\ ${ }^{1}$ Department of Agronomy, National Chiayi University, Chiayi 600, Taiwan. \\ ${ }^{2}$ Department of Food Science, National Chiayi University, Chiayi 600, Taiwan. \\ ${ }^{3}$ Department of Biochemical Science and Technology, National Chiayi University, Chiayi 600, Taiwan.
}

Accepted 18 May, 2018

\begin{abstract}
Adzuki bean (Vigna angularis) is an important crop in Taiwan, Japan and many countries. The bean varieties Kaohsiung No. 8 (KS8) and No. 9 (KS9) were grown in the spring of 2013 and 2014 at an organic certified farm and harvested at maturity from two organic cultivation management systems: organic with integrated pest management (OIPM) and organic without pest management (OWPM). The harvested seeds from OIPM and OWPM cultivations were compared for yield characteristics, seed chemical composition, and seed antioxidant capacity. The yield characteristics were significantly higher in OIPM than OWPM cultivation in 2013 and 2014 of both KS8 and KS9 varieties. The chemical composition of the two varieties for both years showed that OIPM cultivation had relative higher ash and crude protein contents, whereas OWPM produced significantly higher carbohydrate content. The OWPM cultivation expressed higher ABTS and DPPH antioxidant abilities, as well as contained higher total phenolic and flavonoid contents than OIPM. In conclusion, the OIPM increase the yield of Adzuki bean products, whereas OWPM cultivation expose the plants to pests and diseases occurring may increase the antioxidant activity and components. It may suggest that OWPM enhance the chance of the plants responding by inducing a protection system to prevent pathogen attack.
\end{abstract}

Keywords: Adzuki bean (Vigna angularis), organic integrated pest management (OIPM), organic without pest management (OWPM), antioxidant capacity.

*Corresponding author: E-mail: liaohf@mail.ncyu.edu.tw.

\section{INTRODUCTION}

Adzuki bean (Vigna angularis) is an annual leguminous plant. It is often called "red bean" because most of the cultivars produce red colored beans. Adzuki beans are suitable for growing in warm climates, while intolerant of low temperature, high altitude, and dry environments; therefore, its production is limited to East Asia. According to the 2009 Taiwan Agriculture Statistics Annual Report (Tseng, 2009), Adzuki bean has a cultivation area of 6,089 hectares and a yield of 2,096 kg per hectare, giving an annual output of 12,763 metric tons. In Taiwan,
Kaohsiung and Pingtung are the largest growing areas, with cultivation occurring during autumn and winter. In recent years, regions in the South including Yunlin, Chiayi and Tainan have also been cultivated, and the main cultivars planted are Kaohsiung No. 8 (KS8) and No. 9 (KS9). Adzuki bean seed coat contains numerous active antioxidant ingredients, mainly polyphenols, with an important role in scavenging free radicals. Adzuki beans have the highest ferrous ion-chelating ability of all the leguminous plants. Adzuki bean contains various active 
substances, such as polyphenols, tannins, and anthocyanins, all of which have strong antioxidant properties (Zhao et al., 2009). In Japan, polyphenols are considered as the seventh nutrient, after dietary fiber (Deng et al., 2012).

Organic agriculture was combined with traditional agriculture and intercropping systems, the planting of green manure, covering and biological control of weeds and pests, and the maintenance of ecological balance, while not adversely affecting agricultural output. Hsu and Tsai (2001) and Karkanis et al. (2007) suggested that organic agriculture would be utilized as a form of sustainable agriculture. Excessive use of pesticides in the past has destroyed the balance between pests and their natural enemies, leading to the current problems experienced with pests. Therefore, organic farms have begun to use integrated pest management (IPM) methods to reduce pests and diseases, including biological controls, animal materials, microbial materials, plant materials, insect pheromones, and physical controls (Boerma, 1972). Tseng (2009) recommended the use of organic cultivation and management techniques to establish a good farming system, including the use of organic fertilizers, selection of resistant varieties and early species, fertilizer management, adoption of biological control, antagonistic bacteria, and use of natural insecticides. To maintain the concept of sustainable agriculture, crop quality and yield, as well as environmental ecology, must achieve equilibrium (Hsieh, 2014). Ma et al. (2008) used organic soybean cultivation with IPM to enhance pest management on agronomic traits such as yield, pests and diseases. A study by Hou et al. (2008) on potatoes grown using organic cultivation with IPM also showed that the number of pests and diseases in leaves and soil can effectively be reduced using this management system, while maintaining the same levels of production.

Research on the post-harvest preservation and antioxidant capacity of berry fruit by US Agricultural Research Service Center found that different soils, temperature, UV light, and ripening levels could affect the total phenolic and anthocyanin content of the blueberries and raspberries (Chin, 2010). After flowering, the pod color of Adzuki bean begins to change, and can be prepared for harvest. In the same period, the antioxidant activity undergoes rapid changes. Articles have reported that there is a significant change in antioxidant activity in the late phase of crop maturation (Kevers et al., 2011). Jiang et al. (2014) looked at grapes grown in different regions that had the same temperature but differing rainfall levels, and noted that the grapes grown in areas of lower rainfall had higher total phenolics and anthocyanin contents. This suggests that sunshine intensity and the number of sunny days also affect anthocyanin contents. Zhang et al. (2015) demonstrated that too much water during the growth period of peanuts would reduce both the yield and the antioxidant capacity. Supporters of organic agriculture have claimed that organic products have a higher phenolic content, mainly because they are not sprayed with insecticide, and this may mean that the plant is exposed to stresses that induce the synthesis of natural plant defense compounds (Winter and Davis, 2006). Reyes et al. (2007) suggested that plants in stressful conditions induce the synthesis of secondary metabolites, in particular by the regulation of phenylalanine ammonia lyase (PAL) activity, resulting in more phenolic compounds being produced.

Therefore, the present study aimed to demonstrate the effect of organic integrated pest management (OIPM) and organic without pest management (OWPM) on pest control and yield, and to clarify how the crop gains resistance to harmful insects through polyphenol production. Adzuki bean yield characteristics, chemical composition, and antioxidant capacity were also examined. The results are important as a reference for the promotion of spring cultivation of organic Adzuki bean.

\section{MATERIALS AND METHODS}

\section{Materials and field trial planning}

Adzuki bean varieties, that is, KS8 and KS9 were planted on January 23, 2013 and January 27, 2014, respectively, at an organic certified farm in Putzu (Chiayi County, Taiwan), then harvested at the end of April and early May, respectively. The field trial plan included organic cultivation, with integrated pest management (OIPM) and without pest management (OWPM). As shown in Figure 1 , the test plots for planting were repeated three times, each test plot representing one of two sets of variant factors: A) cultivation and management (OIPM and OWPM) described above, and B) the varieties (KS8 and KS9). Each plot was $10 \mathrm{~m}^{2}$, consisting of two furrows and planted in two lines (line spacing of $35 \times 7.5 \mathrm{~cm}$ ). For both OIPM and OWPM, $2400 \mathrm{~kg} / \mathrm{ha}$ of organic fertilizer $\left(\mathrm{N}: \mathrm{P}_{2} \mathrm{O}_{5}\right.$ : $\left.\mathrm{K}_{2} \mathrm{O}=2: 2.5: 2\right)$ with total organic content was $45 \%$ before sowing. For the OIPM treatment, a yellow sticky insect-trap was placed every $5 \mathrm{~m}$, and two sex pheromone-induced traps (for Spodoptera litura and Spodoptera exigua) were set up in each 0.1 ha. Every week, a mixture of pepper extract (300-fold dilution), hydrophilic Melia azedarach oil (500-fold dilution), Bacillus subtilis (500-fold dilution), $48.1 \%$ Bacillus thuringiensis (Bt) water dispersible granules (1000-fold dilution) were sprayed on the farmland as part of the OIPM treatment. In contrast, the OWPM area was cultivated using standard organic procedures during the Adzuki bean growth period, but without the use of any biological agents or any other materials.

\section{Investigation of the yield characteristics of Adzuki beans}

The mature plants with red (mature) pods were obtained from 10 plants per plot, and the yield characteristics including yield per plot were investigated. The yield characteristics surveyed were as follows:

1. Number of mature pods. The number of ripe pods per Adzuki bean plant.

2. Number of total pods. The number of pods harvested per hectare.

3. Weight of dry pods. The total weight of the mature pods per Adzuki bean plant (g).

4 Number of seeds. The number of seeds per Adzuki bean plant. 

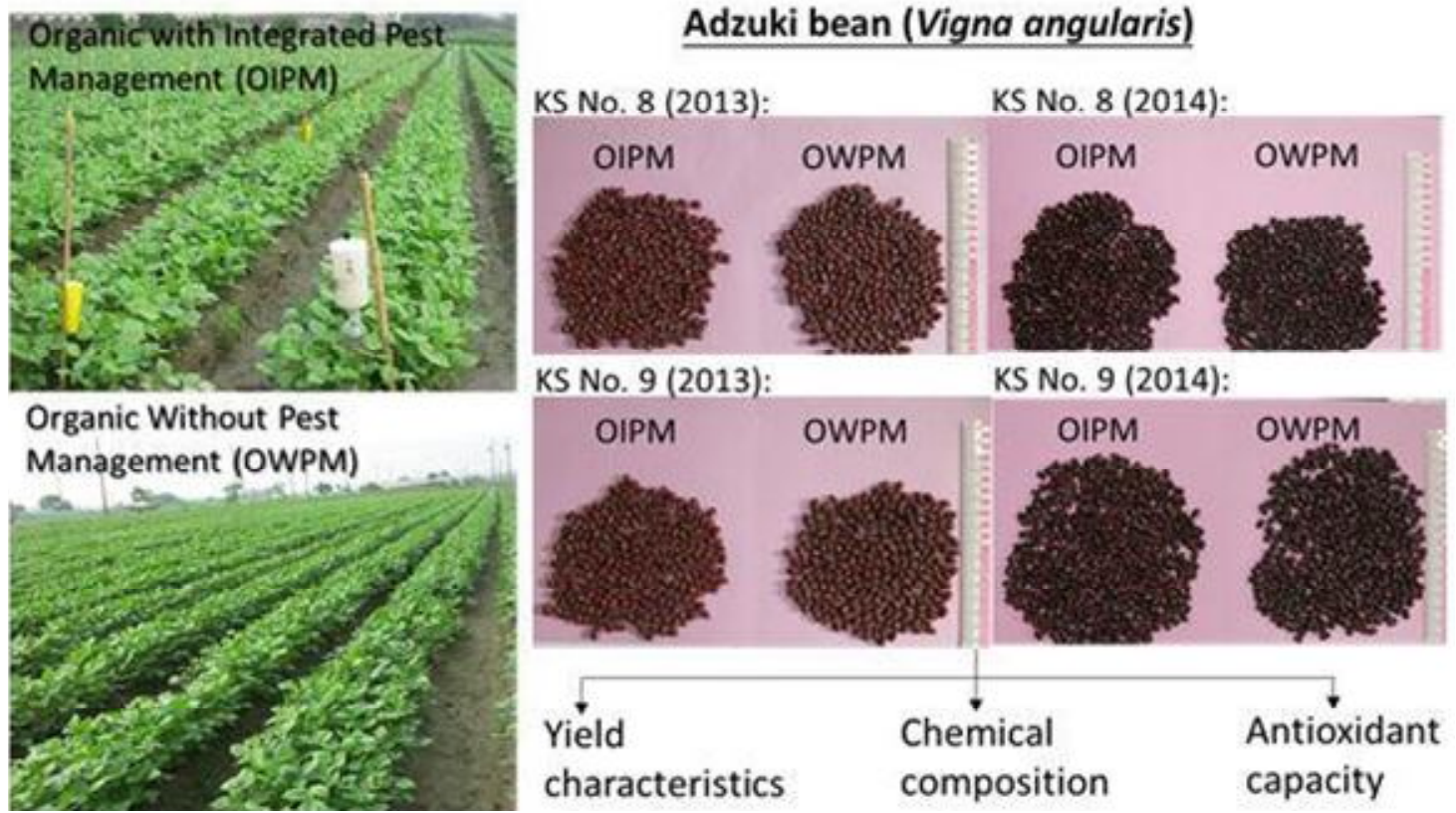

Figure 1. The cultivation of Adzuki bean varieties KS8 and KS9 by using organic cultivation with (OIPM) and without (OWPM) pest management for comparison their performance in yield characters, chemical composition, and antioxidant capacity.

5. Weight of seeds. Seed weight per Adzuki bean plant ( $\mathrm{g}$ ). 6. Seed yield/plot. For each plot $\left(10 \mathrm{~m}^{2}\right)$, the seeds of 10 Adzuki plants were harvested, and the total weight of the output of the plot was calculated.

\section{Analysis of chemical constituents of Adzuki bean seeds}

Adzuki bean pods were collected from KS8 and KS9 cultivars (for both OIPM and OWPM cultivation methods), oven-dried at $32^{\circ} \mathrm{C}$ for $72 \mathrm{~h}$, and then the pods were removed and seeds collected.

Moisture, protein, fat, and ash contents were determined according to the methods of AOAC (1990), carbohydrate content (that is, Nitrogen Free Extracts) obtained by difference. Carbohydrate was determined using the method of Liu et al. (1993), who removed the above components (moisture, inorganic ash, fat, protein) from Adzuki beans, and then assumed that the remaining content would be carbohydrates.

\section{Analysis of Adzuki bean antioxidant activity}

Adzuki bean extracts were prepared. Briefly, Adzuki bean pods (KS8 and KS9 by OIPM and OWPM) were air-dried at $32^{\circ} \mathrm{C}$ for 72 $\mathrm{h}$, and then the collected seeds were ground into powder. For $0.5 \mathrm{~g}$ of Adzuki bean powder sample, $10 \mathrm{ml}$ of analytical grade methanol was added, and the mixture was ultrasonicated for $30 \mathrm{~min}$, then centrifuged at $8,000 \mathrm{rpm}$ for $10 \mathrm{~min}$, and the supernatant was used as the sample solution. The antioxidant analyses were as follows:

1. DPPH assay for free radical scavenging ability: $1 \mathrm{mg} / \mathrm{ml}$ gallic acid (Sigma) standard dissolved in methanol was serially diluted in a 96-well plate. Then $100 \mu \mathrm{l} /$ well of the test samples, methanol blanks, and standard were added, followed by $100 \mu \mathrm{l} /$ well of $1 \mathrm{mM}$ DPPH (2,2-diphenyl-1-picrylhydrazyl) solution. This was left to react at $25^{\circ} \mathrm{C}$ in the dark for $30 \mathrm{~min}$, and the absorbance at wavelength $517 \mathrm{~nm}$ was determined using an ELISA plate reader. Each reaction was performed in triplicate and the scavenging effect of free radicals was calculated as the $50 \%$ scavenging concentration $\left(\mathrm{SC}_{50}\right)(\mathrm{mg} / \mathrm{ml})$. Scavenging effect $(\%)=1-\left[\left(\frac{\mathrm{AS}-\mathrm{AC}}{\mathrm{AC}}\right)\right] \mathrm{X} 100$, where AS is sample absorbance and AC is blank absorbance.

2. ABTS $^{+}$Assay: A volume of $14 \mathrm{mM}$ 2,2'-azino-bis (3ethylbenzothiazoline- 6-sulphonic acid) (ABTS) solution was mixed well with an equal amount of $4.9 \mathrm{mM}$ potassium persulfate solution, and reacted at $25^{\circ} \mathrm{C}$ in the dark for $16 \mathrm{~h}$. The product is an ABTS free-radical solution (dark blue green). Then $100 \mu \mathrm{l} /$ well of the test samples, methanol blank, and standard, as described above for the DPPH assay, were added to $100 \mu \mathrm{L} /$ well of $\mathrm{ABTS}^{+}$free radical solution, reacted at $25^{\circ} \mathrm{C}$ for $6 \mathrm{~min}$, and the absorbance at wavelength $734 \mathrm{~nm}$ was determined using an ELISA plate reader. Each reaction was performed in triplicate and the antioxidant effect and the $50 \%$ scavenging concentration $\left(\mathrm{SC}_{50}\right) \quad(\mathrm{mg} / \mathrm{ml})$ were calculated. ABTS scavenging effect $(\%)=1-\left[\left(\frac{\mathrm{AS}-\mathrm{AC}}{\mathrm{AC}}\right)\right] \mathrm{X} 100$, where AS is sample absorbance and AC is blank absorbance.

\section{Analysis of antioxidant content}

Adzuki bean extracts were prepared according to the previous methods. The antioxidant contents were analysis as follows:

\section{Total phenolic (polyphenols) content}

The method for this assay was based on Tsao and Yang (2003). In brief, a $20 \mu \mathrm{l}$ aliquot of sample solution, $80 \mu \mathrm{l}$ of $7.5 \% \mathrm{Na}_{2} \mathrm{CO}_{3}$, and $100 \mu \mathrm{l}$ of Folin-Ciocalteu phenol reagent were mixed well in a 96well plate. After reaction at $25^{\circ} \mathrm{C}$ for $8 \mathrm{~min}$, the absorbance at 562 $\mathrm{nm}$ was determined using an ELISA plate reader. Gallic acid 
$(1 \mathrm{mg} / \mathrm{ml})$ was used as the standard, and the total phenolic content was estimated from the absorbance of the sample solution, using the calibration curve.

\section{Flavonoid content}

A $500-\mu \mathrm{l}$ aliquot of sample solution, $2.5 \mathrm{ml}$ of distilled water, and $150 \mu \mathrm{l}$ of $5 \% \mathrm{NaNO}_{2}$ were mixed well and allowed to stand for 5 min. This was then mixed with $300 \mu \mathrm{l}$ of $10 \% \mathrm{AlCl}_{3}$ and allowed to stand for a further $5 \mathrm{~min}$. Then, $1 \mathrm{ml}$ of $1 \mathrm{M} \mathrm{NaOH}$ and $550 \mu \mathrm{l}$ of distilled water were added to the reaction, and the absorbance at wavelength $510 \mathrm{~nm}$ was determined for a $100 \mu \mathrm{l}$ aliquot in a microwell using an ELISA plate reader. Quercetin $(1 \mathrm{mg} / \mathrm{ml}$, Sigma) was used as a standard, and the flavonoid content was estimated from the absorbance of the sample solution, using a calibration curve.

\section{Total anthocyanin content}

The method for this assay was based on the previous study by Fuleki and Francis (1968). In brief, $1483 \mu \mathrm{l}$ of sample solution and $17 \mu \mathrm{l}$ of $32 \%(0.1 \mathrm{~N}) \mathrm{HCl}$ solution were mixed, heated at $100^{\circ} \mathrm{C}$ for $60 \mathrm{~min}$, and the absorbance was measured at wavelengths 530, 620 and $650 \mathrm{~nm}$ using a spectrophotometer. Optical density of anthocyanins $\mathrm{OD}_{\lambda}=\left(\mathrm{OD}_{530}-\mathrm{OD}_{620}\right)-0.1\left(\mathrm{OD}_{650}-\mathrm{OD}_{620}\right)$; anthocyanin content $(\mathrm{nmol} / \mathrm{g})=\left(\mathrm{OD}_{\lambda} / \mathcal{E}\right) \times(\mathrm{V} / \mathrm{m}) \times 10^{6}$, where $O D_{\lambda}$ is the absorbance of anthocyanins at $530 \mathrm{~nm}, \mathcal{E}$ is anthocyanin Mohr extinction coefficient (Zapsalis and Francis 1965) $4.62 \times 10^{4}, \mathrm{~V}$ is extraction solution volume, and $\mathrm{m}$ is sample weight $(\mathrm{g})$.

\section{Statistical analysis}

Comparison of yield characteristics and chemical composition analysis data for the different cultivation methods were performed using SAS 9.1 statistical software for the comparison of mean differences between the least significant differences (LSD).

\section{RESULTS}

\section{Effects of different cultivation management on Adzuki bean yield}

As shown in Table 1, OIPM showed higher results for the number of mature pods (30.75), the total pod number (37.6), the number of seeds per plant (206.5), the weight of seeds per plant $(24.76 \mathrm{~g})$, and seed yield $(8,245.1$ $\mathrm{g} / 10-\mathrm{m}^{2}$ ) in 2013. In addition, there was no significant difference in dry pod weight. Moreover, the yield results for the spring of 2014 for the Adzuki bean KS8 culture using OIPM and OWPM cultivation methods (Table 1). By OIPM cultivation method, an average of 109.20 seeds per plant were produced, which was significantly higher than the seed number of OWPM cultivation method. There were no significant differences in the number of mature pods, total pods, weight of dry pods, seed weight per plant, and seed yield per plot between the two cultivation methods.

In 2013, OIPM showed higher results for the number of total pod (26.72) and the number of seeds per plant
(138.10). In addition, the yield characteristics for the spring of 2014 for the Adzuki bean KS9 showed the number of seeds per plant (96.42) was significantly higher in OIPM than the OWPM cultivation method. There were no significant differences $(p>0.05)$ in the number of mature pods, total pods, pod dry weight, seed weight per plant, and seed yield per plot between these two cultivation methods (Table 2).

\section{Effects of different cultivation and management on chemical constituents of Adzuki bean seeds}

Results showed that in 2013 and 2014, KS8 bean with the OIPM cultivation produced significantly higher ash content (5.24 and 5.70\%, respectively) than the OWPM cultivation. The OWPM cultivation method produced higher level of carbohydrate content (59.85 and 57.23\%, respectively) than the OIPM cultivation. The mean values for moisture, crude fat, and crude protein showed a relative higher in OIPM, but there was no statistical difference (Table 3).

Table 4 presents the chemical composition of the Adzuki bean KS9 for spring 2013 and 2014, cultivated using OIPM and OWPM methods. The OIPM cultivation produced higher crude protein content $(24.43$ and $26.21 \%$ respectively in 2013 and 2014 ) than the OWPM cultivation method, whereas the carbohydrate content from beans grown using the OWPM cultivation method (58.45 and $58.47 \%$, respectively) was significantly higher than from those using the OIPM cultivation. Similarity, the mean values of moisture, ash, and crude fat content are a relative higher in OIPM, but there shown no significant difference between the two cultivation methods.

\section{Effects of different cultivation and management methods on the antioxidant capacity of Adzuki beans}

Table 5 presents the antioxidant activity and composition of the Adzuki bean KS8 for spring 2013 and 2014, comparing the use of OIPM and OWPM cultivation methods. The antioxidant activities by $\mathrm{ABTS}^{+}$and $\mathrm{DPPH}$ assay showed that OWPM have better effect (that is, lower concentration of $\mathrm{SC}_{50}$ ) than the OIPM cultivation. Especially by the DPPH assay, OWPM cultivation has significantly higher antioxidant effect than OIPM in both years. Additionally by using the OWPM cultivation method, the total phenolic content and the flavonoid content of Adzuki bean KS8 were significantly higher than that for the OIPM cultivation in 2013. However, there were no significant differences in anthocyanin content between these two cultivation methods in 2013 and 2014.

Table 6 presents the antioxidant activity and composition of Adzuki bean KS9 for spring 2013 and 2014, using the OIPM and OWPM cultivation methods. The $\mathrm{SC}_{50}$ concentrations of $\mathrm{ABTS}^{+}$and $\mathrm{DPPH}$ for the 
Table 1. Effects of OIPM and OWPM on yield characteristics of Adzuki bean KS8 in 2013 and 2014, spring crop

\begin{tabular}{|c|c|c|c|c|c|c|}
\hline Treatment & $\begin{array}{l}\text { No. of mature pods } \\
\text { (No./plant) }\end{array}$ & $\begin{array}{l}\text { No. of total pods } \\
\text { (No./plant) }\end{array}$ & $\begin{array}{c}\text { Weight of } \\
\text { dry pods (g) }\end{array}$ & $\begin{array}{l}\text { No. of seed } \\
\text { (No./plant) }\end{array}$ & $\begin{array}{l}\text { Weight of } \\
\text { seed }(g)\end{array}$ & $\begin{array}{c}\text { Seed yield } \\
/ \text { plot }\left(\mathrm{g} / 10-\mathrm{m}^{2}\right)\end{array}$ \\
\hline \multicolumn{7}{|l|}{2013} \\
\hline OIPM $^{2}$ & $30.75^{a}$ & $37.60^{\mathrm{a}}$ & 32.41 & $206.50^{\mathrm{a}}$ & $24.76^{a}$ & $8245.10^{a}$ \\
\hline OWPM $^{2}$ & $20.00^{b}$ & $23.70^{\mathrm{b}}$ & 26.21 & $150.30^{b}$ & $18.56^{b}$ & $6180.48^{b}$ \\
\hline $\mathrm{LSD}_{0.05}$ & 4.05 & 3.60 & ns & 53.54 & 5.18 & 1820.2 \\
\hline \multicolumn{7}{|l|}{2014} \\
\hline OIPM $^{2}$ & 16.53 & 17.77 & 15.20 & $109.20^{a}$ & 12.13 & 4039.30 \\
\hline OWPM $^{2}$ & 15.33 & 15.96 & 14.96 & $96.30^{b}$ & 12.11 & 4032.63 \\
\hline $\mathrm{LSD}_{0.05}$ & ns & ns & ns & 10.63 & ns & ns \\
\hline
\end{tabular}

${ }^{1}$ Means in the same column followed by the same letter are not significantly different for LSD test $P<0.05$. ${ }^{2}$ OIPM: Organic with integrated pest management. OWPM: Organic without pest management. ns: no significant difference.

Table 2. Effects of OIPM and OWPM on yield characteristics of Adzuki bean KS9 in 2013 and 2014, spring crop ${ }^{1}$.

\begin{tabular}{|c|c|c|c|c|c|c|}
\hline Treatment & $\begin{array}{c}\text { No. of mature } \\
\text { pods (No./plant) }\end{array}$ & $\begin{array}{l}\text { No. of total pods } \\
\text { (No./plant) }\end{array}$ & $\begin{array}{l}\text { Weight of dry } \\
\text { pods }(\mathrm{g})\end{array}$ & $\begin{array}{l}\text { No. of seed } \\
\text { (No./plant) }\end{array}$ & $\begin{array}{l}\text { Weight of } \\
\text { seed }(g)\end{array}$ & $\begin{array}{c}\text { Seed yield } \\
\text { /plot }\left(\mathrm{g} / 10-\mathrm{m}^{2}\right)\end{array}$ \\
\hline \multicolumn{7}{|l|}{2013} \\
\hline OIPM $^{2}$ & 21.69 & $26.72^{a}$ & 31.60 & $138.10^{a}$ & 27.63 & 9200.8 \\
\hline OWPM $^{2}$ & 20.40 & $22.51^{b}$ & 28.32 & $130.68^{b}$ & 25.08 & 8540.4 \\
\hline $\mathrm{LSD}_{0.05}$ & ns & 2.35 & ns & 7.23 & ns & ns \\
\hline \multicolumn{7}{|l|}{2014} \\
\hline OIPM $^{2}$ & 15.33 & 16.92 & 14.21 & $96.42^{a}$ & 13.43 & 4468.86 \\
\hline OWPM $^{2}$ & 15.42 & 16.13 & 13.32 & $82.42^{b}$ & 12.66 & 4285.71 \\
\hline LSD $_{0.05}$ & ns & ns & ns & 12.05 & ns & ns \\
\hline
\end{tabular}

Table 3. Effects of OIPM and OWPM on seed chemical composition of Adzuki bean KS8 in 2013 and 2014, spring crop".

\begin{tabular}{|c|c|c|c|c|c|}
\hline Treatment & Moisture (\%) & Ash (\%) & Crude fat (\%) & Crude protein (\%) & Carbohydrate (\%) \\
\hline \multicolumn{6}{|l|}{2013} \\
\hline OIPM $^{2}$ & 12.82 & $5.24^{\mathrm{a}}$ & 0.77 & 22.77 & $58.33^{b}$ \\
\hline OWPM $^{2}$ & 12.32 & $4.43^{b}$ & 0.70 & 22.36 & $59.85^{a}$ \\
\hline $\mathrm{LSD}_{0.05}$ & ns & 0.61 & ns & ns & 1.32 \\
\hline \multicolumn{6}{|l|}{2014} \\
\hline OIPM $^{2}$ & 10.55 & $5.70^{a}$ & 0.95 & 27.21 & $55.58^{b}$ \\
\hline OWPM $^{2}$ & 10.25 & $4.93^{b}$ & 0.93 & 26.74 & $57.23^{a}$ \\
\hline $\mathrm{LSD}_{0.05}$ & ns & 0.52 & ns & ns & 1.28 \\
\hline
\end{tabular}

OIPM cultivation were higher than that of the OWPM cultivation, especially by the $\mathrm{ABTS}^{+}$assay in 2014 showed a significant difference between these two cultivation methods. The results indicated that KS9 beans by OWPM cultivation have better antioxidant activity than OIPM. Moreover, the antioxidant components total phenolic and flavonoid content were significantly higher for OWPM than the OIPM cultivation. The anthocyanin 
Table 4. Effects of OIPM and OWPM on seed chemical composition of Adzuki bean KS9 in 2013 and 2014, spring crop $^{1}$.

\begin{tabular}{lccccc}
\hline Treatment & Moisture (\%) & Ash (\%) & Crude fat (\%) & Crude protein (\%) & Carbohydrate (\%) \\
\hline 2013 & & & & & \\
OIPM $^{2}$ & 13.15 & 4.74 & 0.71 & $24.43^{\mathrm{a}}$ & $57.14^{\mathrm{b}}$ \\
OWPM $^{2}$ & 13.82 & 4.72 & 0.77 & $22.18^{\mathrm{b}}$ & $58.45^{\mathrm{a}}$ \\
$\mathrm{LSD}_{0.05}$ & $\mathrm{~ns}$ & $\mathrm{~ns}$ & $\mathrm{~ns}$ & 1.92 & 1.12 \\
& & & & & \\
2014 & & & & & \\
OIPM $^{2}$ & 9.55 & 5.62 & 0.86 & $26.21^{\mathrm{a}}$ & 57.85 \\
OWPM $^{2}$ & 9.69 & 5.30 & 1.04 & $25.59^{\mathrm{b}}$ & 58.47 \\
LSD $_{0.05}$ & $\mathrm{~ns}$ & $\mathrm{~ns}$ & $\mathrm{~ns}$ & 0.57 & $\mathrm{~ns}$ \\
\hline
\end{tabular}

${ }^{1}$ Means in the same column followed by the same letter are not significantly different for LSD test $P<0.05 .{ }^{2}$ OIPM: Organic with integrated pest management. OWPM: Organic without pest management. ns: no significant difference.

Table 5. Effects of OIPM and OWPM on seed antioxidant capacity and composition of Adzuki bean KS8 in 2013 and 2014, spring crop".

\begin{tabular}{|c|c|c|c|c|c|}
\hline Treatment & $\begin{array}{c}\text { ABTS }^{+} \\
\left(\mathrm{SC}_{50}{ }^{3}, \mathrm{mg} / \mathrm{ml}\right)\end{array}$ & $\begin{array}{c}\text { DPPH } \\
\left(\mathrm{SC}_{50}{ }^{3}, \mathrm{mg} / \mathrm{ml}\right)\end{array}$ & Total phenolics (mg/g) & Flavonoid $(\mathrm{mg} / \mathrm{g})$ & Anthocyanin $(\mathrm{mg} / \mathrm{g})$ \\
\hline \multicolumn{6}{|l|}{2013} \\
\hline OIPM $^{2}$ & 13.59 & $21.37^{\mathrm{a}}$ & $10.94^{b}$ & $4.53^{b}$ & 1.86 \\
\hline OWPM $^{2}$ & 13.43 & $18.92^{b}$ & $11.65^{\mathrm{a}}$ & $5.05^{a}$ & 1.84 \\
\hline $\mathrm{LSD}_{0.05}$ & ns & 2.20 & 0.63 & 0.47 & ns \\
\hline \multicolumn{6}{|l|}{2014} \\
\hline $\mathrm{OIPM}^{2}$ & 17.28 & $45.35^{\mathrm{a}}$ & 11.25 & 4.85 & 1.59 \\
\hline $\mathrm{OWPM}^{2}$ & 17.08 & $31.95^{b}$ & 11.68 & 4.79 & 1.67 \\
\hline $\mathrm{LSD}_{0.05}$ & ns & 1.23 & ns & ns & ns \\
\hline
\end{tabular}

${ }^{1}$ Means in the same column followed by the same letter are not significantly different for LSD test $P<0.05$. ${ }^{2}$ OIPM: Organic with integrated pest management. OWPM: Organic without pest management. ${ }^{3} \mathrm{SC}_{50}: 50 \%$ concentration of scavenging. ns: no significant difference.

Table 6. Effects of OIPM and OWPM on seed antioxidant capacity and composition of Adzuki bean KS9 in 2013 and 2014, spring crop $^{1}$.

\begin{tabular}{lccccc}
\hline Treatment & $\left.\mathbf{A B T S}^{+}{ }^{+} \mathbf{S C}_{\mathbf{5 0}}{ }^{3}, \mathbf{m g} / \mathbf{m l}\right)$ & $\mathbf{D P P H}\left(\mathbf{S C}_{\mathbf{5 0}}{ }^{3}, \mathbf{m g} / \mathbf{m l}\right)$ & $\begin{array}{c}\text { Total phenolics } \\
(\mathbf{m g} / \mathbf{g})\end{array}$ & $\begin{array}{c}\text { Flavonoids } \\
(\mathbf{m g} / \mathbf{g})\end{array}$ & $\begin{array}{c}\text { Anthocyanin } \\
(\mathbf{m g} / \mathbf{g})\end{array}$ \\
\hline 2013 & & & & & \\
$\mathrm{OIPM}^{2}$ & 7.77 & 21.12 & $11.60^{\mathrm{b}}$ & $3.60^{\mathrm{b}}$ & 1.41 \\
$\mathrm{OWPM}^{2}$ & 7.41 & 20.75 & $12.24^{\mathrm{a}}$ & $3.84^{\mathrm{a}}$ & 1.64 \\
$\mathrm{LSD}_{0.05}$ & $\mathrm{~ns}$ & $\mathrm{~ns}$ & 0.42 & 0.20 & $\mathrm{~ns}$ \\
& & & & & \\
2014 & & & & & \\
$\mathrm{OIPM}^{2}$ & $15.32^{\mathrm{a}}$ & 44.95 & 12.51 & $3.82^{\mathrm{b}}$ & 1.36 \\
$\mathrm{OWPM}^{2}$ & $12.82^{\mathrm{b}}$ & 43.86 & 12.60 & $5.48^{\mathrm{a}}$ & 1.38 \\
$\mathrm{LSD}_{0.05}$ & 2.21 & $\mathrm{~ns}$ & $\mathrm{~ns}$ & 0.92 & $\mathrm{~ns}$ \\
\hline
\end{tabular}

${ }^{1}$ Means in the same column followed by the same letter are not significantly different for LSD test $P<0.05$. ${ }^{2}$ OIPM: Organic with integrated pest management. OWPM: Organic without pest management. ${ }^{3} \mathrm{SC}_{50}: 50 \%$ concentration of scavenging. ns: no significant difference.

content in KS9 beans was not significantly different $(p>$ $0.05)$ between the two cultivation methods in both 2013 and 2014.

\section{DISCUSSION}

The present study assessed the effects of different 
cultivation management, including organic cultivation with (OIPM) and without (OWPM) pest management, on Adzuki bean varieties KS8 and KS9 in 2013 and 2014 for their performance in yield characters, chemical composition, and antioxidant capacity.

Compare the yield characteristics for the Adzuki bean KS8 (Table 1) and KS9 (Table 2) demonstrated that there have similar results in OIPM and OWPM cultivation. The OIPM cultivation produced higher yield than OWPM. Although the variation of weather between 2013 and 2014, as well as the species diversity between KS8 and KS9 of the Adzuki beans, OIPM cultivation have better yield performance than OWPM (Tables 1 and 2). Ma et al. (2008) who studied the effect of pest management on agronomic traits, yields, pests, and disease for organically cultivated soybeans, indicated that organic integrated pest control management (OIPM) could improve the yield of organic vegetable soybeans. Therefore, the present study results in both 2013 and 2014 have the similar finding for the two Adzuki bean species of KS8 and KS9.

The pests and diseases of Adzuki bean included powdery mildew, root rot, bean lizard, tawny moth, aphid and the insects belong to Thripidae, Aleyrodidae, Cicadellidae families in Taiwan. Due to the long-term organic and disease-free pest management and cultivation, the land environment has biodiversity and achieves the control effect of pest restriction with each other. Therefore, the pests and diseases in OWPM are not serious enough to have a certain yield in our study. In the area of OIPM by conventional plowing, weeding, soil cultivar, and fertilizer management, we also used pheromone traps of Spodoptera litura and Spodoptera littoralis, yellow sticky paper, as well as application of Bacillus thuringiensis to reduce the pest density.

Additionally, the leaf senescence may cause the different of yield of Adzuki bean between 2013 and 2014. Chou and $\mathrm{Wu}$ (2003) suggested that in spring, the deciduous leaves of the Adzuki bean were lost after the plants had attained their highest accumulation of pods. In the 2-year test period of the Adzuki bean using OIPM cultivation method, its deciduous leaf loss began after flowering and leaf withering occurred earlier than under the OWPM method. Therefore, it may be the reason that OIPM increase more yield characteristics than OWPM cultivation.

It is possible that the density of natural insect enemies plays an important role in the control of pests and diseases for the organic cultivation management. Most of the problematic insects are parasitic insects, which are controlled by ladybugs (including diarrheal ladybugs), that are of considerable help in suppressing pests and their induced diseases. Zehnder et al. (2007) demonstrated that the use of OIPM cultivation methods for planned arthropod pest management, without the use of chemical pesticide, is successful in combination with insect control using biological and mineral insecticides, including such methods as prophylactic/inundative and inoculation strategies, pheromones/repellents, and crop trapping. Biological control can also affect natural pests. Bengtsson et al. (2005) measured the ratio of natural pests over many years using organic farming, and showed that the density of natural pests in fields using the OWPM cultivation method was approximately 1.2-times higher than in those using the OIPM cultivation method. This increase in species richness was particularly noticeable in the increase in predatory insects, which reduced the number of pests by preying on them. Mohamed et al. (2000) studied the control of wheat aphid (Diuraphis noxia) by its natural enemies in organically grown cultivars, with the results indicating that increased natural insect enemies can reduce wheat production loss by $61 \%$. Other report by Swezey et al. (2006) investigated 6 years of continuous cotton growth using the OIPM and OWPM cultivation methods, and showed that although no significant differences in plant growth and insect population abundance occurred, the yield under OIPM was higher than that under OWPM cultivation. Therefore, the weather, species, leaf senescence, and natural insect enemy density may influence the experiments reported here. This study demonstrated that Adzuki bean with OIPM cultivation achieved higher levels of yield than the plants grown using OWPM cultivation methods.

When comparing OIPM and OWPM cultivation methods on chemical constituents of Adzuki bean seeds, OIPM produced significantly higher ash and crude protein content respectively for Adzuki bean KS8 and KS9 cultivars in both 2013 and 2014 . We suggested that the cultivated species might cause the differential performance of Adzuki bean. Moreover, the carbohydrate composition was higher for OWPM than for OIPM in both KS8 and KS9 of both 2013 and 2014. These findings are similar to the report by Yang (1999) who indicated that differing methods of cultivating peanuts changes the chemical composition of the seeds. Itoh et al. (2004) studied the composition of Adzuki beans, including crude fat, crude protein, and other characteristics, and found that these varied depending on the impact of environmental differences. Comparison of the results for the OIPM and OWPM cultivation methods presented here showed significant differences in carbohydrate content, demonstrating that the chemical composition might be controlled by the different cultivation (Tables 3 and 4).

In this study, we also found that the antioxidant activities analysis by $\mathrm{ABTS}^{+}$and DPPH scavenging free radical ability were significantly higher using the OWPM than the OIPM cultivation method of Adzuki bean. The major antioxidant components, including the total phenolic and flavonoid content, were higher in Adzuki beans KS8 and KS9 grown using the OWPM cultivation method than for those grown using the OIPM cultivation method in spring 2013 and 2014 (Tables 5 and 6). Similar results were reported by Fernandes et al. (2012) by comparison the differences in antioxidant activity of 
strawberries between the OIPM and OWPM cultivation methods, and found that higher total phenolic and anthocyanin content in strawberries grown using the OWPM cultivation method. The possibility of the result is the organic culture with pests and disease in Adzuki bean may stimulate the plant to response a protective effect against pathogens. Rivero et al. (2001) pointed out that environmental stress would cause the plant to transmit cellular signals, initiating biological secondary metabolites to induce synthesis and accumulation of flavonoids, and thus to suppress oxidation. Fukasawa-Akada et al. (1996) also reported that plants in nutrient-rich environments could produce phenolic compounds as a defense mechanism against fungal, bacterial, and microbial infestation and infection. An article showed that the use of pesticides or biological agents caused plants to become more susceptible to pathogens, which would lead to the plant to produce higher levels of phenolic compounds as a means to protect themselves (Yang, 1999). In this study, the OWPM method of cultivation without pest management produced higher antioxidant content than the OIPM cultivation method. This may be because the higher exposure to pests and diseases occurring under the cultivation method may increase the chance of the plants responding by inducing a protection system to prevent pathogen attack (Fernandes et al., 2012).

\section{Conclusions}

The present study demonstrated that Adzuki bean (Vigna angularis) varieties KS8 and KS9 were grown in the spring of 2013 and 2014 by two organic cultivation management systems (OIPM, OWPM), showed OIPM cultivation achieved higher levels of yield than the plants grown using OWPM cultivation methods. However, the OWPM cultivation methods showed significant higher levels in carbohydrate content than OIPM cultivation. In addition, the OWPM method of cultivation without pest management produced higher antioxidant content and antioxidant activity than the OIPM cultivation. It was suggested that the higher exposure of Adzuki bean to pests and diseases occurring under the cultivation method might increase the protection system, such as the production of phenolic compounds, to prevent pathogen attack.

\section{ACKNOWLEDGEMENTS}

Our appreciation goes to Hou $\mathrm{C} \mathrm{J}$ and colleges in Department of Agronomy, National Chiayi University (Chiayi, Taiwan) who provided the assistance of Adzuki bean collection. This work was supported by Grants MOST 105-2320-B-415-002 and 102-2321-B-415-011 from the National Science Council of the Republic of China, Taipei, Taiwan. The authors declare no competing financial interest.

\section{REFERENCES}

AOAC, 1990. The official methods of analysis of the association of official analytical chemists. 15th ed. The Association of Official Analytical Chemists Arlington, Virginia, USA.

Bengtsson J, Ahnstrom J, Weibull AC, 2005. The effects of organic agriculture on biodiversity and abundance: a meta-analysis. J Appl Ecol, 42: 261- 269.

Boerma AH, 1972. The CMEA integration plan. FAO. The State of Food and Agriculture, 59-60.

Chin YR, 2010. Adzuki beans Kaohsiung 9. Kaohsiung District Agricultural News Bulletin, 72: 14-14.

Chou KL, Wu ST, 2003. Studies on growth stages for different leaf abscission genotypes in adzuki bean varieties. Research Bulletin of Kaohsiung District Agricultural Research and Extension Station, 14: 24-38

Deng MF, Pu SJ, Wan P, Lei GJ, 2012. Identification and evaluation of oxidation resistance adzuki bean germplasm resources. Chin Agric Sci Bull, 28: 59-64.

Fernandes VC, Domingues VF, de Freitas V, Delerue-Matos C, Mateus $\mathrm{N}$, 2012. Strawberries from integrated pest management and organic farming: Phenolic composition and antioxidant properties. Food Chem, 134: 1926-1931.

Fukasawa-Akada T, Kung SD, Watson JC, 1996. Phenylalanine ammonia-lyase gene structure, expression, and evolution in Nicotiana. Plant Mol Biol, 30: 711-722.

Fuleki T, Francis FJ, 1968. Quantitative methods for anthocyanins. J Food Sci, 33: 266-274.

Hou CJ, Lee RS, Wen YY, Huang CC, 2008. Studies on the organic cultivation of sweet potato. Proc Symp Organ Crop Culture Technol, 83-126.

Hsieh TF, 2014. Development trend of plant source protective agents. Agric Biotechnol Industry Dev Seminar Special Issue, 121: 117-140.

Hsu HS, Tsai YH, 2001. Establishment of crop rotation system for organic farming. Research Bulletin of Kaohsiung District Agricultural Improvement Station (Taiwan), 12: 37-54.

Itoh T, Itoh Y, Mizutani M, Fujishiro K, Furuichi Y, Komiya T, Hibasami H, 2004. Hot-water extracts from adzuki beans (Vigna angularis) suppress not only the proliferation of KATO III cells in culture but also benzo (a) pyrene-induced tumorigenesis in mouse forestomatch. $J$ Nutr Sci Vitaminol, 50: 295-299.

Jiang B, Luo MJ, Zhang XZ, Zhang ZW, 2014. Analysis of phenolic content and antioxidant capacity of grape wine in different areas. Food Ferment Ind, 10: 146-150.

Karkanis A, Bilalis D, Efthimiadou A, 2007. The effect of green manure and irrigation on morphological and physiological characteristics of Virginia (flue-cured) organic Tobacco (Nicotiana tabaccum). Int $J$ Agric Res, 2: 910-919.

Kevers C, Pincemail J, Tabart J, Defraigne O, Dommes J, 2011. Influence of cultivar, harvest time, storage conditions, and peeling on the antioxidant capacity and phenolic and ascorbic acid contents of apples and pears. J Agric Food Chem, 59: 6165-6171.

Liu YF, Ferng S, Chiou RYY, Tsai CL, 1993. Processing related characteristics of peanut kernels of various cultivars grown in Taiwan. J Technol Taiwan, 8: 73-80.

Ma CH, Su FC, Lin MY, Chen CH, Wang TC, Tsai HH, Juroszek P, Yang RY, Chen LH, Palada MC, 2008. Integrated production technologies for organic vegetable soybean. Proc Symp Organ Crop Culture Technol, 61-82.

Mohamed AH, Lester PJ, Holtzer TO, 2000. Abundance and effects of predators and parasitoids on the Russian wheat aphid (Homoptera: Aphididae) under organic farming conditions in Colorado. Environ Entomol, 29: 360-368.

Reyes LF, Villareal E, Cisneros-Zevallos L, 2007. The increase in antioxidant capacity alter wounding depends on the type of fruit or vegetable tissue. Food Chem, 101: 1254-1262.

Rivero RM, Ruiz JM, Garcia PC, Lopez-Lefebre LR, Sanchez E, Romero L, 2001. Resistance to cold and heat stress: accumulation of phenolic compounds in tomato and watermelon plants. Plant Sci, 160: 315-321.

Swezey SL, Goldman P, Bryer J, Nieto D, 2006. Six-year comparison between organic, IPM and conventional cotton production systems in 
the Northern San Joaquin Valley, California. Renew Agric Food Syst, 22: $30-40$.

Tsao R, Yang R, 2003. Optimization of a new mobile phase to know the complex and real polyphenolic composition: towards a total phenolic index using high-performance liquid chromatography. J Chromatogr A, 1018: 29-40.

Tseng SH, 2009. Cereal crops organic cultivation practice. Taichung District Agricultural Improvement Field Special Issue (Taiwan), 96: 87-95.

Winter CK, Davis SF, 2006. Organic Foods. J Food Sci, 71: 117-124.

Yang $\mathrm{AH}, 1999$. Peanut nutrition and processing products. Tainan District Agricultural Improvement Field Technical Special Issue, 88: 98-103.

Zapsalis C, Francis FJ, 1965. Cranberry anthocyanins. J Food Sci, 30: 396-399.

Zehnder G, Gurr GM, Kühne S, Wade MR, Wratten SD, Wyss E, 2007. Arthropod pest management in organic crops. Ann Rev Entomol, 52: 57-80.

Zhang J, Liu J, Zang XW, Tang FS, Dong WS, Xu J, Miao LJ, Zhang $Z X, 2015$. Effects of drought stress on peanut yield and metabolic regulation in different growth stages. J Nuclear Agric Sci, 29: 11901197.

Zhao CJ, Fan ZH, Zhou W, 2009. Research progress on health functions of red Adzuki bean. Chin Agric Sci Bull, 11: 46-50.
Citation: Hou C, Chen ZC, Ferng SH, Liao HF, 2018. Effects of organic cultivation with and without pest management of Adzuki bean (Vigna angularis) on yield characteristics, seed chemical composition, and antioxidant capacity. Net J Agric Sci, 6(2): 20-28. 